\title{
A Human Culture Based Discussion and Class Practice to Statics Friction
}

\author{
Ke-sheng WANG* \\ No.2006, XiYuan Avenue, Chengdu, Sichuan Province, P.R.China, 611731 \\ ${ }^{*}$ Corresponding author
}

Keywords: Statics friction, Engineering education, Tao Te Ching, Connecting study.

\begin{abstract}
Nowadays, the higher education class is transforming from knowledge transfer base to ability cultivating place. How to make full use of Chinese tradition culture and let it play a role in the classroom teaching has become a serious research topic. This paper is to investigate a connection between a classical engineering teaching topic friction with Chinese classical book of Tao Te Ching. A typical engineering problem can be interpreted in terms of a human culture based understanding. By practically using this connection in the real class teaching, it is found that it may help students to establish the sense of connecting studies and interests in both human culture and engineering problems. This paper is an innovative practice in engineering education through including of human culture knowledge.
\end{abstract}

\section{工程静力学之静摩擦力的人文探讨课堂实践}

\author{
王科盛* \\ 电子科技大学机械与电气工程学院, 成都市高新西区西源大道2006号, 611731 \\ “通讯作者
}

关键字: 静摩擦力; 工程教育; 道德经; 关联学习

摘要: 当今, 高校的课堂正在从知识传播的主战场向能力培养的主阵地迅速转向。作为具有悠 久历史的我国, 如何发挥自己传统文化的积淀, 在以学生能力为输出导向的工程教育体系中 贡献力量已经成为中国当代教师责无旁贷的历史使命。本文通过作者在一线教学过程中的实 践体会, 将工程静力学中的静摩擦力知识与道德经的经典语句结合融入课堂讨论, 探索了工 科问题人文化理解在课堂教学中的作用。通过深入挖掘中国传统文化的内涵, 创造性地关联 传统文化与工程问题, 培养学生关联性学习的意识和兴趣, 本文的工作是中国文化在工程教 育中独特优势的探索性实践。

\section{1. 引言}

随着国际工程教育理念在我国高校的不断推进和认可, 高校的课堂正在从知识传播的主 战场向能力培养的主阵地迅速转向。必须肯定的说, 对学生能力的培养必将在不久的将来放在 整个教育过程的中心位置。作为具有悠久历史的我国, 如何发挥自己传统文化的积淀, 在以 学生能力为输出导向的工程教育体系中贡献力量也必将成为中国当代教师责无旁贷的历史使 命。有人说 “知识的数量会淹没智慧”, 在课堂教学中让学生体会不同门类知识之间的内在关 联，提炼和思考知识的内涵关联，已经成为当今大学课堂教师所面临的共同课题。

建立于各种节点之上的关联主义学习是当今学习模式的重要特征, 持续性的关联性学习 能力将比知识的掌握更为重要[1]。中国作为当下的教育大国和未来的教育强国, 如何深入挖 
掘中国传统文化的内涵, 创造性地关联传统文化与工程问题, 培养学生关联性学习的意识和 兴趣, 将是中国特色工程教育的独特优势。

本文来源于作者在一线教学过程中的实践体会，将工程知识的意义与人文内涵结合，在 工科氛围浓厚的工程力学课堂中, 把工程静力学中的静摩擦力知识与道德经的经典语句结合, 探索工科问题人文化理解在课堂教学中的作用。课堂实践表明, 教师在人文知识引入的情境 下, 不但可以打破安静的课堂, 增加课堂讨论的参与度, 而且可以激发学生思维的广度和深 度，培养跨界关联、跨界思考的意识。下文将就工程力学中的静摩擦力讲授环节说明工科知 识的关联性人文探讨的课堂实践，不当之处，敬请读者批评指正。

\section{2. 工科知识的关联性人文探讨实践}

\section{1 课堂讲授环节引入 - 静摩擦力}

传统的讲授内容: 摩擦是一个看似简单, 实则非常复杂的物理现象。摩擦力当中最与众 不同的非静摩擦力莫属。有人认为静摩擦力实际上不应该算作摩擦力。其它的摩擦力都与能 量的耗散有关：它使得相互摩擦的物体相对速度降低, 并将机械能转化成其他形式。当两个 物体之间有相对运动时, 摩擦力与运动方向相反。摩擦力的本质, 在几百年来人们一直是莫 衷一是。主流的观点有两种产生机理：凹凸啮合说和粘附说。啮合说认为摩擦力是由相互接 触的物体表面粗糙不平产生的。摩擦粘附论认为摩擦力与两个表面之间的分子引力相关。其 实, 人们通过不断的实验和计算分析, 上述两个理论提出的机理都能产生摩擦, 其中粘附理 论比啮合理论更为普遍。但在不同材料上, 两种机理的表现各有偏向, 如对与金属材料, 产 生的摩擦以粘附作用为主, 而对于木材, 产生的摩擦以啮合作用为主。实际上, 关于摩擦力 的本质, 目前尚未有定论。

\section{2 将课堂知识内容的终点作为起点启发学生思考}

上文是通常过程的课堂讲授内容，如果用现代科学的方法来探究摩擦的本质，很显然， 人们至今尚未彻底了解这个天天与我们相伴的摩擦力, 通常意义的课堂讲授当然可以到此为 止, 教师讲授的完备性已经基本无可指摘。但是, 有经验的老师都会有体会, 这样的内容讲 解往往会让课堂非常安静, 很难充分调动学生的参与, 教师也没有给学生任何参与讨论的空 间。因此, 即便教师费劲心力, 效果其实并不理想, 这是许多教师在教学过程中的一个普遍 “瓶颈”。

爱因斯坦说: 教育不要记住各种事实，而要训练大脑如何思考。在这个“瓶颈”环节，教师 对这个工程现象的认识与分享将是学生在这个环节上真正思考和展开想象的重要契机。学生 诚然可以沿着科学的体系继续设想如何深入细致的研究摩擦现象。但是, 教师完全可以引导 学生进入不同层面、不同知识背景的有趣关联。知识的关联也绝不仅仅是在工科知识范畴之 内, 完全可以鼓励学生跨界和跨学科的思考尝试。

\section{3 教师引领工科知识的人文思考实践-关于静摩擦力}

教师通过典型案例引入学生思考: 前面提到有人认为静摩擦力不应该算摩擦力, 这也许 是一个很出乎意料的观点。但是仔细揣摩, 却十分值得思考。我们先看一个大家都比较熟悉 的斜面滑块问题分析，如图1所示， 


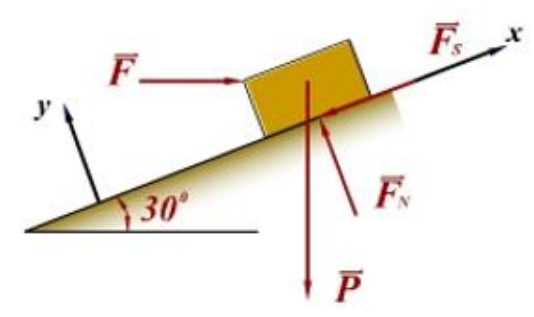

图1 斜面滑块受力分析图

上图是物理模型中最为典型的滑块斜面问题, 当滑块保持静止不动的时候, 我们可以很 快地根据推力 $\mathrm{F}$ 和重力 $\mathrm{P}$ 分析出这个问题当中的摩擦力 $F_{S}$ 。

这个问题的实质就是物块的重力 $\mathrm{p}$ 与向上的推力 $\mathrm{F}$ 之间的平衡博弯。当重物比较重的时 候, 力 $\mathrm{F}$ 不够大, 物体有向下运动的趋势, 摩擦力就沿着斜面向上帮助推力保持物块的平衡。 当重物比较轻的时候, 力 $\mathrm{F}$ 足够大, 物块有向上运动的趋势, 此时摩擦力则变转方向沿着斜面 向下，帮助重力保持物块的平衡。

教师通过分享启发学生关联思考: 上述讨论, 我们可以得到好几个非常有趣的发现, 大 家可以与老师一起来思考:

静摩擦力可有（重力水平分量与推力不相等时）、可无（重力水平分量与推力相等时） 方向不定，根据平衡状态发生变化。

教师与学生分享自己的思考一: 静摩擦力的这个特点与《道德经》第七十七章: 天之道, 其犹张弓与? 高者抑下, 下者举之, 有余者损之, 不足者补之。天之道, 损有余而补不足。

（译文：自然的规律，不是很像张弓射箭吗？弦拉高了就把它压低一些，低了就把它举 高一些, 拉得过满了就把它放松一些, 拉得不足了就把它补充一些。自然的规律, 是减少有 余的补给不足的。)

大家有没有发现，静摩擦力难道不是合乎天道的一个自然事物吗 - 损有余而补不足。重 力向下的分量大了, 它就帮着往上, 推力分量向上的大了, 它就往下拽, 没有人指挥静摩擦 力, 它自然就会做这个事, 在力学的世界里面, 是否还能发现一些其他的现象呢?

课堂的效果: 这时的课堂至少会把睡觉的同学吸引过来, 他们开是注意老师在讲一个完 全不同的事情, 和通常的讲课内容差别很大, 他们开始专注这个新鲜问题。那些专心听课的 同学已经开始会然一笑, 开始思考了, 并且会有自己的一些答案, 课堂开始被搅动起来。

教师与学生分享自己的思考二: 道德经第二章: 有无之相生也, 难易之相成也, 长短之 相刑也, 高下之相盈也, 音声之相和也, 先后之相随, 恒也。

（译文: 有和无互相转化, 难和易互相形成, 长和短互相显现, 高和下互相充实, 音与 声互相谐和, 前和后互相接随——这是永恒的。)

大家有没有发现静摩擦力的重要属性就是有和无相互转化, 随着外界力的变化而发生变 化, 而这种变化在中国人的思想体系里就是永恒啊。长久的拥有不是恒长的啊! 在我们的工 程力学里面有太多这样的现象了, 大家还能否举些例子呢?

课堂的效果: 教师抛出的这个问题其实是比较简单的, 答案可以有各种可能, 这样的问 题最有利于学生开始打破“沉默”开始发表意见，比如有同学提到能力问题，有同学提到不倒 翁等等。自此, 课堂的氛围开始活跃, 同学们开始深入思考, 跃跃欲试地想表达自己的观点 了。

教师与学生分享自己的思考三: 静摩擦力“静而不动”, 不做功, 不产生能量耗散。从力 学的角度来分析, 静摩擦力不会在其方向上产生位移, 因此不会做功, 这与大多数的力的特 点都不一样的。静摩擦力似乎是一个“碌碌无为”的存在, 然而, 所有工程师都清楚, 没有了静 摩擦, 这个世界将完全失去秩序。 
教师引入更高层次的分享: 道德经第七章: 天长, 地久。天地之所以能长且久者, 以其 不自生也，故能长生。

（译文: 天长地久, 天地所以能长久存在, 是因为它们不为了自己的生存而自然地运行 着, 所以能够长久生存。)

静摩擦力实实在在的存在, 但它的存在是以其它力的存在而存在, 其它力不需要它的时 候，它可以不存在，这是怎样一个“无我利他”的力啊。

课堂的效果：教师在这里的分享也许会让部分同学一头雾水，因为这个分享的理解只有 在学生深刻关联上面斜面问题的分析, 并深刻理解摩擦力的特点以后才能领悟到。因此, 教 师可以通过斜面问题的回头看, 再帮助学生理解。这个过程其实就达到了课程的目的, 让学 生锻炼深入思考和关联的能力。而且作者的实践表明, 这样与课堂内容看似不相关而有深刻 内关联的问题对吸引学生思考的效果绝佳。

\section{教师还可以继续解读（视学生理解灵活掌握）：}

如果, 不仔细分析是很难察觉静摩擦力存在的, 这难道不是“以其不自生也, 故能长生” 的道理吗？静摩擦力实在是“低调”, 不显山露水, 好像并不需要它, 可是一旦失去, 就难保太 “平”，整个世界都将会失去秩序（关联思考一和二）。而且，它还是一个“虚空”的力，有了它 能量既不增也不减（关联静摩擦力不做功）, 这也许就是摩擦力无处不在, 而且可以长久存 在的原因吧。

课堂的效果：问题分享到这个层面，其实已经把工程问题上升到了哲学层面。作者课堂 教学的实践也表明, 大部分学生是很难在这个层面有深入领悟的, 但是总有少数的同学会感 兴趣课下与老师探讨。所谓个性化的教育, 也许就是体现在这里了, 有特别兴趣的同学自然 会与老师继续的讨论, 笔者认为教师能够打开学生兴趣的大门, 这段教学的作用就真正实现 了。

\section{3. 总结}

威尔谢尔在《道德沦丧的大学》一书中认为[2]，大学的目标是帮助学生找到分化的知识 领域间暗藏的内在联系, 以便学生回答“我们是谁”、“我们应该如何处世”之类的深层次问题。 大学的工科教育绝不仅仅是冰冷的知识要素和知识体系, 深入挖掘工科知识的人文内涵, 帮 助学生建立跨学科知识结点的关联, 是启发学生积极思考的有效手段之一, 也是培养学生终 生学习的一种重要手段。

作者的实践表明，通过教师三个层次的工科知识人文分享，课堂从打破静默，到各抒己 见, 再到凤毛麟角的少数同学课后讨论, 整个教学过程调动了学生的思考, 激发了学习的兴 趣, 同时更重要的是作者深切的感受到, 教师对所讲授问题的深入理解是开展个性化教学, 激发学生兴趣的一个有效手段。看似没有分别的学生们其实每个人都不同, 教师持续不断的 在各种问题上有不同的见解, 必然会激发不同特质的同学对课程内容的兴趣, 作者也相信这 将是对年轻的学生们影响深远的教育。正如托尔斯泰所说: “知识只有当它靠积极思维得来的 时候才是真正的知识”。作为教育工作者, 笔者认为, 这也是教师应当努力在课堂教学中深入 挖掘的“教学改革”关键所在，真正陪伴学生思维的前进。

\section{References}

[1] George Siemens. Connectivism: A learning theory for the digital age. Instructional Technology and distance learning, 2005(1), 3-10

[2] Bruce Wilshire. The Moral Collapse of the University Professionalism, Purity, and Alienation. State University of New York Press. 1990. 